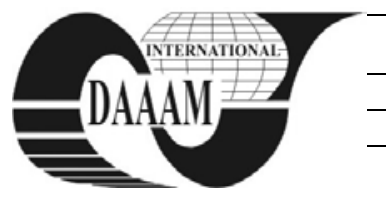

\title{
INFLUENCE OF CROSS-LINKING ON PROPERTIES OF PEVA USED FOR CABLE SHEATHS
}

\author{
PINKEROVA, M[artina] \& POLANSKY, R[adek]
}

\begin{abstract}
Polyethylene vinyl acetate (PEVA) is a material widely used among others in cable industry for halogen-free cable insulation. A manufacturing blend is not a pure polymer; it contains various additives such as for example flame retardants. The paper compares properties of a basic granulate with properties of a produced cross-linked cable sheath. Thermal effects were analysed both in positive and negative temperatures in the temperature range from $-150{ }^{\circ} \mathrm{C}$ to $700{ }^{\circ} \mathrm{C}$. Differential scanning calorimetry, thermogravimetry and dynamical mechanical analysis were applied. The obtained results showed, that melting temperature, glass transition temperature, heat of fusion and crystallinity of the material decrease whereas tensile strength and temperature of thermal decomposition increase with PEVA cross-linking.

Key words: cable sheaths, PEVA, glass transition, thermal analyses
\end{abstract}

\section{INTRODUCTION}

Polymers are considered to be basic materials for industrial manufacture. Their low price, simplicity of manufacture and wide modification flexibility of their properties are the main reasons for their rapid development. More and more new types of plastics are developed for application in all sorts of branches. Not only is the development of new materials important, it is also relevant to research the modification and combination of already known polymers by processes of copolymerization, filling or addition of various additives. An investigation of materials for special use occurring in places with the danger of fire is regarded as interesting field of cable industry. In the case of these materials, the emphasis is placed on providing the cable functionality in fire for definite period of time. These insulating materials are widely used mainly in tunnel constructions of underground and elevator shafts, where they provide emergency escape. Additives protecting from the spread of fire are called flame retardants. $\mathrm{Al}(\mathrm{OH})_{3}$, known as $\mathrm{ATH}$ and $\mathrm{Mg}(\mathrm{OH})_{2}-\mathrm{MDH}$ are two best known halogen-free flame retardants. Places, where cables are permanently exposed to negative operating temperatures, are the other examples of special usage of these materials. At these temperatures the glass transition occurring in the insulation material influences its properties (especially elasticity). Operation of insulation material at ambient temperature (i.e. above the glass transition temperature) is necessary for keeping its elasticity.

\section{BACKGROUND}

Copolymer of ethylene and vinyl acetate (PEVA) is a polymer which is similar to elastomers due to its elasticity; nevertheless it can be produced in the same way as thermoplastic polymers. Materials with VA content of $40-$ $70 \%$ are known as oxidation cross-linkable rubbers with excellent thermal resistivity for which they are used for cable sheaths. Apart from these materials, many others are used see (Mladenovic \& Weindl, 2009). This paper describes the behaviour of a halogen-free granulate compared to produced cross-linked cable sheath. The aim of the paper is to specify the influence of cross-linking on material properties. The measured samples differ in their material structure, as the structure changes significantly during the cross-linking. At negative temperatures, the cross-linking influences the glass transition temperature, when material loses its elasticity, at positive temperatures then the cross-linking influences material stability at higher temperatures and crystallinity. According to (ReyesLabarta et al., 2006), the cross-linking is based on formation of chemical bonds between adjacent molecular chains to form a 3D network.

Thermal decomposition of PEVA is divided into two steps. As noted by (Hull et al., 2003), EVA loses acetic acid during the first one; this is displayed in the temperature interval from 300 to $350{ }^{\circ} \mathrm{C}$. The second decomposition step involves random chain scission of the remaining material, forming unsaturated vapour gases such as butene or ethylene. Rapid and autocatalytic cross-linking of the PEVA occurs during its thermal degradation.

Two different PEVA samples were analysed by thermal analyses. Dynamic mechanical analysis (DMA) was used to characterize and interpret the mechanical properties in negative temperature range. DMA is a technique in which the viscoelastic behaviour of the sample under oscillatory load is monitored as a function of temperature while the sample is subjected to a controlled temperature programme. The samples were measured by apparatus TA Instruments TMA Q400EM in penetration mode. Static force of $0.3 \mathrm{~N}$ was applied, modulated force was $\pm 0.2 \mathrm{~N}$ at frequency of $1 \mathrm{~Hz}$. The samples were subjected to linear temperature heat with heating rate of $5{ }^{\circ} \mathrm{C} / \mathrm{min}$ under air atmosphere in the temperature range from -150 to $100^{\circ} \mathrm{C}$.

Simultaneous thermal analysis (STA) was applied for measure in positive temperatures. STA enables simultaneous determination of some physico-chemical processes (such as changes of enthalpy, changes of mass, melting point etc). In this case STA is a combination of differential scanning calorimetry (DSC) and thermogravimetry (TG). Measured data were collected on a TA Instruments SDT Q600 analysis. Being places in open platinum cups, the samples $(\sim 12 \mathrm{mg})$ were tested from ambient temperature to $700{ }^{\circ} \mathrm{C}$, at a temperature scanning rate of $10^{\circ} \mathrm{C} / \mathrm{min}$ under air atmosphere.

\section{RESULTS AND DISCUSSION}

\subsection{Dynamic mechanical analysis}

The samples of both uncross-linked and cross-linked PEVA were measured on DMA apparatus. This analysis allows separation of the viscoelastic material response to two components of complex modulus: a real part $\mathrm{E}^{\prime}[\mathrm{MPa}]$ and an imaginary part $\mathrm{E}^{\prime \prime}$ [MPa]. The real part represents a storage modulus, which characterizes elasticity of material and the imaginary part represents a damping part (loss modulus) which describes a viscosity of the material. Phase angle between these moduli is defined as a loss factor $\tan \delta$.

DMA results of the uncross-linked sample are shown in Fig. 1, while Fig. 2 presents the DMA results of the cross-linked sample. The glass transition temperature was analysed from the 
storage modulus curve, where deflection from a basic line (from positive to negative temperatures) defines a temperature at which the material starts to lose its elasticity.

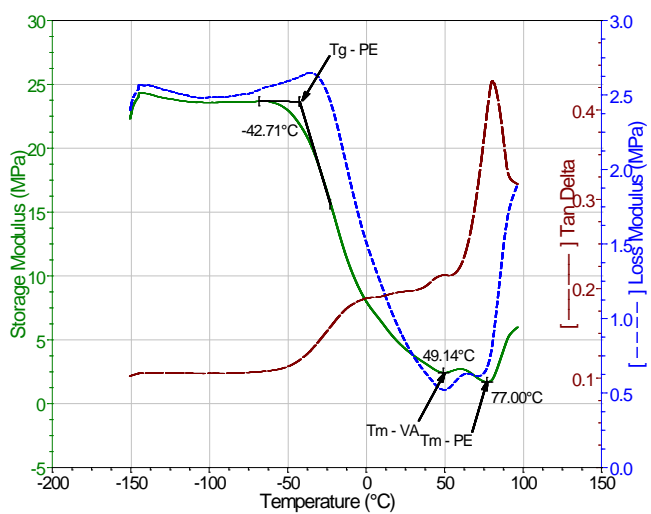

Fig. 1. DMA results of uncross-linked sample

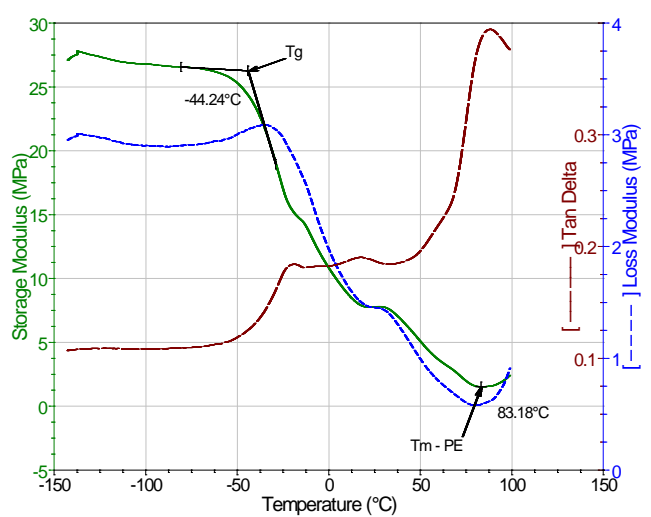

Fig. 2. DMA results of cross-linked sample

The increase of storage modulus in the case of the crosslinked material is observed as well as slight shift of the glass transition temperature to negative temperatures due to the cross-linking. The glass transition temperature of about $-30{ }^{\circ} \mathrm{C}$ has been confirmed by (Sung et al., 2005). There are two peaks (Fig. 1) in positive temperatures which present melting point of two different crystalization types: VA and PE type. This confirms an immiscibility of crystalization phases as described by (Faker et al., 2008). As obvious, two peaks became one in Fig. 2 (area of PEVA melting point) due to the cross-linking, compared to opposite effect in Fig. 3. Different measuring technique might be an explanation, as in DMA measurement the sample is exposed to thermo-mechanical stress while in DSC measurement the sample is exposed only to heat. Change of loss modulus curve is also obvious, loss modulus increases and loss factor decreases due to the cross-linking (Shivakumar et al., 2005). With increasing temperature also new peaks appear on the storage and loss modulus curves.

\subsection{Differential scanning calorimetry}

Figure 3 shows a comparison of DSC and TGA curves of the samples. The melting point area $\left(45-80^{\circ} \mathrm{C}\right)$ was described above. In thermal decomposition area of flame retardant, there is marked start of exothermic reaction, which changes to endotermic reaction just due to the flame retardant. Quite a large amount of remaining material also proves the presence of flame retardant. The Fig. 3 also shows less intensity of flame retardant reaction due to the cross-linking, which is also obvious on TG curve. The first deflection of cross-linked material TG curve is slightly shifted towards higher temperatures. The first decomposition reactions of PEVA start in the temperature of around $325^{\circ} \mathrm{C}$, which agrees with (Hull et al., 2003). Subsequently a protective layer is formed and it retards combustion unless it is damaged. It decomposes completely at the temperature of around $430{ }^{\circ} \mathrm{C}$. According to (Reyes-Labarta et al., 2006), melting point, heat of fusion and crystallinity of the material decreases and thermal decomposition temperature increases. These effects are also presented in Fig. 3.

Fig. 3. DSC and TGA results of both samples

\section{CONCLUSION}

The difference between both the cross-linked and the uncross-linked materials has been demonstrated very well. At the negative temperatures, PEVA passes through its glass transition (from -44 to $-42{ }^{\circ} \mathrm{C}$ ) and it becomes fragile. In the area of positive temperatures $\left(45-80^{\circ} \mathrm{C}\right)$, the melting occurs and so does the thermal decomposition at very high temperatures (from 400 to $430{ }^{\circ} \mathrm{C}$ ). The experiment confirmed that cross-linking improves physic-chemical properties of this material.

\section{ACKNOWLEDGEMENTS}

This article was carried out with the support of Ministry of Education, Youth and Sports of Czech Republic, MSM 4977751310.

\section{REFERENCES}

Faker, M., Razavi Aghjeh, M., K., Ghaffari, M., Seyyedi, S.A. (2008). Rheology, morfology and mechanical properties of polyetylene/etylene vinyl acetate copolymer (PE/EVA) blends. European Polymer Journal, Vol. 44, No. 6 April 2008, p. 1834-1843, ISSN 1834-1842

Hull, T.R., Price, D., Liu, Y., Wills, C.L., Brady, J. (2003). An investigation into the decomposition and burning behaviour of Ethylene-vinyl acetate copolymer nanocomposite materials. Polymer Degradation and Stability, Vol. 82, No. 2, p. 365-371, ISSN 0141-3910

Mladenovic, I., Weindl, Ch. (2009). ICAAS - Integrated system for lasting Accelerated Aging of MV Cables, Data Monitoring and Acquisition. Proceedings of CEIDP, 18-21 October 2009, Virginia Beach, VA, ISSN 0084-9162, ISBN 978-1-4244-4557-8, pp. 35 - 38, IEEE, New York

Reyes-Labarta, J.A., Olaya, M.M., Marcilla, A. (2006). DSC and TGA study of the transitions involved in the thermal treatment of binary mixtures of PE and EVA copolymer with a crosslinking agent. Polymer, Vol. 47, No. 24, October 2006, p. 8194-8202, ISSN 8194-8202

Shivakumar, E., Das, C.K., Segal, E., Narkis, M. (2005). Viscoelastic properties of ternary in situ elastomer composites based on fluorocarbon, acrylic elastomers and thermotropic liquid crystalline polymer blends. Polymer, Vol. 46, No. 10, March 2005, p. 3363-3371, ISSN 33633371

Sung, Y.T., Kum, C.K., Lee, H.S., Kim, J.S., Yoon, H.G., Kim, W.N. (2005). Effects of crystallinity and crosslinking on the thermal and rheological properties of ethylene vinyl acetate copolymer. Polymer, Vol. 46, No. 25, October 2005, p. 11844-11848, ISSN 0032-3861 